\title{
Dynamics of cancer in Republic of Tatarstan and approaches to development of mathematical methods for analysis of clinical trials
}

\author{
Savdur S.N. \\ Kazan Federal University, Institute of management, \\ economics and finance \\ Kazan, Russia \\ savdur.svetlana@yandex.ru \\ Stepanova Yu.V. \\ Kazan Federal University, Institute of management, \\ economics and finance \\ Kazan, Russia \\ juliyas64@mail.ru
}

\author{
Fessina Ye.L. \\ Kazan Federal University, Institute of management, \\ economics and finance \\ Kazan, Russia
}

\author{
Kodolova I.A. \\ Kazan Federal University, Institute of management, economics and finance \\ Kazan, Russia \\ kiak6@mail.ru
}

\begin{abstract}
The official statistics enabled one to analyze the dynamics of epidemiological indicators of oncological pathology in the Republic of Tatarstan over 2011-2015. The paper considers analysis results of the epidemiological prevalence of cancer in the region based on the indicators of the overall morbidity and mortality of the population. The correlation of morbidity rates in the same age groups of male and female are analyzed. A conclusion is drawn about the unfavorable trend in the development of oncological diseases in the republic. The authors also consider theoretical questions of determining mathematical models parameters of oncological diseases to solve applied problems related to the processing of immunological experiments data and clinical observations. They defined approaches to the construction of a model of some hypothetical disease; this model takes into account the development patterns of a certain class of diseases. The facts resulting from various studies and relating to individual aspects of the disease process are systematized and various immunological hypotheses are studied. The tasks to determine the mathematical model parameters from the data of clinical observations using methods of mathematical modeling are set. The research considers approaches to the solution of such tasks as applied to the mathematical model for immune reactions of the body. The role of mathematical models in studying external influences on the dynamics of pathologic processes in the
\end{abstract}

body is shown with the aim of developing strategies and tactics of treatment.

Keywords- dynamics of the process, comparative analysis, mathematical models, differential equations, generalizing indicators, assessment of efficiency.

Rising incidence of malignant neoplasms in the Russian Federation and around the world is a pressing issue over the last several decades. It requires a multifaceted approach to assessing the oncological epidemiological situation, taking into account the comprehensive analysis of databases related to the incidence and mortality of the population, including those from malignant neoplasms (MNP). In 2015, there were 589,341 cases of MNP in the Russian Federation, including 270,046 and 319,335 cases in male and female patients, respectively. The growth of this indicator in 2015 compared to 2014 was $4.0 \%$ [1].

In 2015, the leading localizations in the overall structure of oncological incidence in the Russian Federation were skin $(12.5 \%$, with melanoma $14.2 \%)$, mammary gland (11.4\%), trachea, bronchi and lung $(10.2 \%)$, colon $(6.6 \%)$, prostate gland $(6.6 \%)$, stomach $(6.4 \%)$, rectum, rectosigmoid compound, anus (4.9\%), lymphatic and hematopoietic tissue $(4.7 \%) \%)$, uterus $(4.1 \%)$, kidney $(3.9 \%)$, pancreas $(3.0 \%)$, cervix $(2.8 \%)$, bladder $(2.7 \%)$, ovary $(2,4 \%)$ [1].

The first positions in the structure of the incidence of malignant neoplasms of the male population of Russia in 2015 
were divided as follows: tumors of trachea, bronchi and lung $(17.8 \%)$, prostate gland $(14.4 \%)$, skin $(10.0 \%$, with melanoma $-11.4 \%)$, stomach $(7.9 \%)$, colon $(6.1 \%)$. The specific relative importance of the malignant neoplasms of rectum, rectosigmoid compound, anus (5.3\%), lymphatic and hematopoietic tissues $(4.8 \%)$, kidneys $(4.6 \%)$, bladder $(4.6 \%)$, pancreas $(3.3 \%)$, larynx $(2.4 \%)$. In terms of specific proportion, the significant group of men form malignant tumors of the urogenital system (24.4\% of all ZNO) (Figure I) [1].

The leading oncological pathology in the female population of Russia in 2015 was mammary gland cancer $(20.9 \%)$, neoplasms of skin $(14.6 \%$, with melanoma $16.5 \%)$, uterus $(7.7 \%)$, colon $(7.1 \%)$, stomach $(5.2 \%)$, cervix $(5.2 \%)$, rectum, rectosigmoid compound, anus $(4.6 \%)$, lymphatic and hematopoietic tissue (4.6\%), ovary (4.4\%), trachea, bronchi, lung $(3.8 \%)$. Thus, the greatest specific proportion in the structure of oncological morbidity for women make malignant neoplasms of the organs of the reproductive system (38.9\%), with tumors of the genitals comprise $18.0 \%$ of all malignant neoplasms for women (Figure II) [1].

In 2015 , the proportion of malignant neoplasms of the digestive system in females was $23.4 \%$ that is lower than that for males $(31.1 \%)$. Every fifth malignant tumor diagnosed in men $(21.4 \%)$ is localized in the respiratory system. The share of these tumors in women is almost 5 times lower than that of men $(4.2 \%)$ [1].

The maximum number of diseases falls on the age group of 65-69 (16.1\%): for men - 18.4\%, for women - 14.3\%) [1, p. 34]. The differences in the age structure of the incidence of male and female populations is manifested distinctly after 30 years old. Specific proportion of malignant neoplasms at the age of 30-49 years old in the group of cases among females is higher $(13.5 \%)$ than in the group of afflicted males $(7.9 \%)$ [1, p. 35]. In the age group of 60 years old or over, $68.6 \%$ of cases in men and $64.1 \%$ in female populations are diagnosed [1].

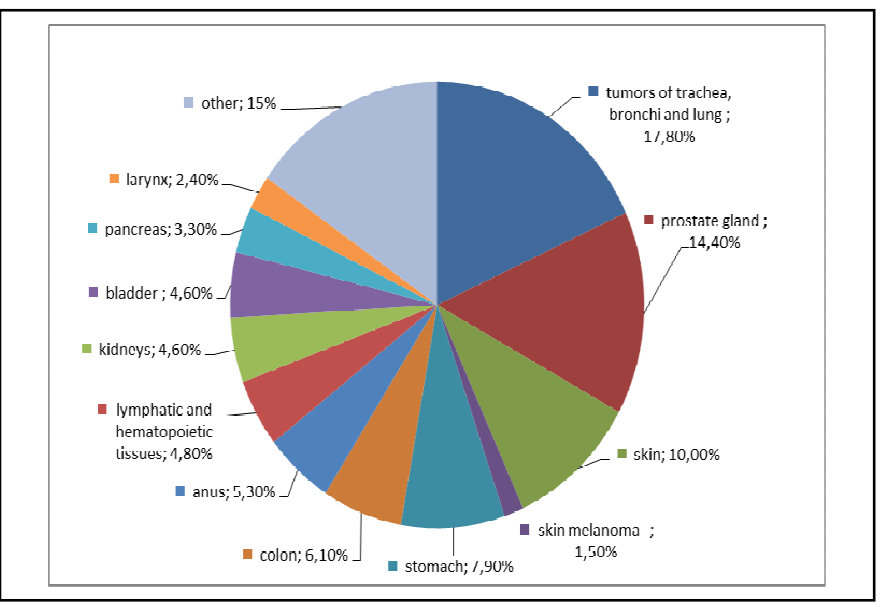

Fig. I. Structure of the incidence of malignant neoplasms of the male population of Russia in 2015
The proportion of malignant neoplasms in children (0-14 years old) among the cases of males is $0.62 \%$ (1684 cases), among the cases of females - $0.47 \%$ (1500 cases). The proportion of malignant neoplasms in children (0-17 years old) among the cases of males is $0.72 \%$ (1955 cases and among the cases of famales $-0.56 \%$ ( 1779 cases). The specific proportion of malignant tumors in adolescents (15-19 years old) is $0.19 \%$ (1116 cases) [1].

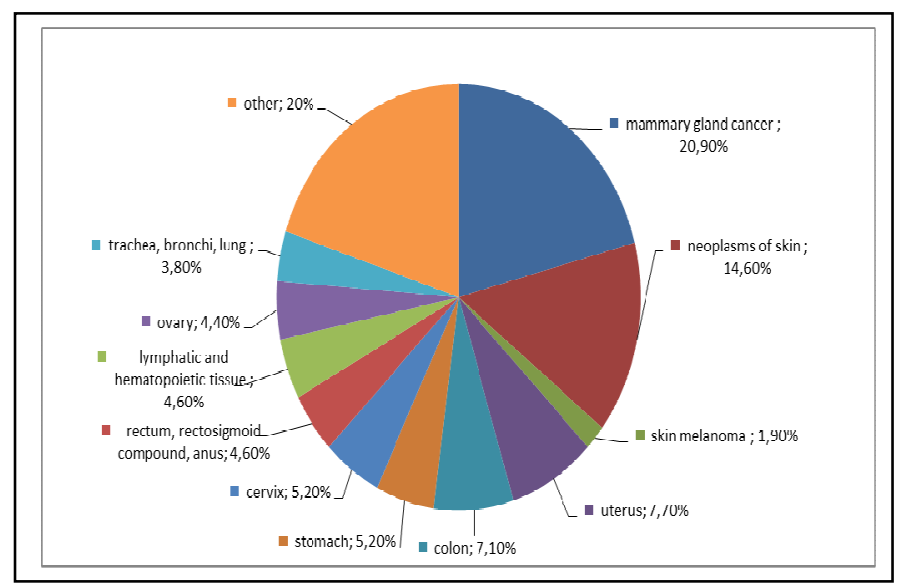

Fig. II. Structure of the incidence of malignant neoplasms of the female population of Russia in 2015

In the Republic of Tatarstan (RT) in 2015, 15,010 people were diagnosed with MNP [2, p. 180]. In RT, there were 91,404 notified cases since determining the diagnosis of MNP in 2015 (Table I) [2].

TABLE I. Incidence of malignancies of the population of the Republic of Tatarstan s for 2011-2015.

\begin{tabular}{|c|c|c|c|c|c|}
\hline Indicators & 2011 & 2012 & 2013 & 2014 & 2015 \\
\hline $\begin{array}{c}\text { Patients } \\
\text { diagnosed } \\
\text { with an } \\
\text { incidence } \\
\text { for the first } \\
\text { time - total }\end{array}$ & 13336 & 13782 & 14185 & 14801 & 15010 \\
\hline $\begin{array}{c}\text { For 100,000 } \\
\text { people }\end{array}$ & 351 & 362 & 370 & 385 & 389 \\
\hline $\begin{array}{c}\text { The number } \\
\text { of patients } \\
\text { registered in } \\
\text { health-care } \\
\text { facilities - } \\
\text { total }\end{array}$ & 70057 & 74761 & 80251 & 85694 & 91404 \\
\hline $\begin{array}{c}\text { For 100,000 } \\
\text { people }\end{array}$ & 1842 & 1956 & 2091 & 2223 & 2363 \\
\hline
\end{tabular}

Comparative analysis of diseases associated with MNP in some districts of the Russian Federation showed significant differences (Table II) [3]. 
TABLE II. MORBIDITY OF THE RUSSIAN POPULATION WITH ONCOLOGICAL NEOPLASMS (REGISTERED DISEASES IN PATIENTS WITH A DIAGNOSIS DETERMINED FOR THE FIRST TIME IN LIFE) FOR 2011-2015.

\begin{tabular}{|c|c|c|c|c|c|}
\hline Year & 2011 & 2012 & 2013 & 2014 & 2015 \\
\hline \multicolumn{6}{|c|}{ per 1000 people of population } \\
\hline $\begin{array}{c}\text { Russian } \\
\text { Federation }\end{array}$ & 11.1 & 11.6 & 11.4 & 11.6 & 11.4 \\
\hline $\begin{array}{c}\text { Central Federal } \\
\text { District }\end{array}$ & 10.6 & 11.7 & 10.3 & 10.5 & 10.2 \\
\hline $\begin{array}{c}\text { North-West } \\
\text { Federal District }\end{array}$ & 12.9 & 12.5 & 12.5 & 12.8 & 13.7 \\
\hline $\begin{array}{c}\text { Southern } \\
\text { Federal District }\end{array}$ & 10.7 & 10.9 & 11.0 & 11.3 & 10.0 \\
\hline $\begin{array}{c}\text { North } \\
\text { Caucasus } \\
\text { Federal District }\end{array}$ & 5.4 & 6.1 & 5.9 & 5.7 & 6.0 \\
\hline $\begin{array}{c}\text { Volga Federal } \\
\text { District }\end{array}$ & 11.9 & 12.3 & 12.5 & 13.1 & 13.1 \\
\hline $\begin{array}{l}\text { Ural Federal } \\
\text { District }\end{array}$ & 10.4 & 10.8 & 11.2 & 11.5 & 11.0 \\
\hline $\begin{array}{c}\text { Siberian } \\
\text { Federal District }\end{array}$ & 12.8 & 13.0 & 13.5 & 13.9 & 13.6 \\
\hline $\begin{array}{c}\text { Far Eastern } \\
\text { Federal District }\end{array}$ & 10.4 & 10.5 & 10.5 & 10.4 & 10.6 \\
\hline $\begin{array}{c}\text { Crimean } \\
\text { Federal District }\end{array}$ & - & - & - & 9.4 & 8.1 \\
\hline
\end{tabular}

According to the data of the table it is clear that in 2015 the North-West Federal District ranked the first in Russia in terms of the incidence of cancer (13.7). It is followed by the Siberian Federal District (13.6) and the Volga Federal District (13.1). The North Caucasus Federal District in 2015 ranked last in Russia in terms of the incidence of cancer (6.0).

Let us consider the results of the analysis of the epidemiological prevalence of MNP in the RT based on morbidity and mortality rates. At the first stage of assessing the effectiveness of medical care for oncological patients, the prevalence of cancer was studied. The epidemiological analysis in the Republic of Tatarstan showed that in 20112015, there was an increase in the primary incidence of MNP: 13,336 people were taken ill in 2011 and 15010 people in 2015 [2]. In 2015, in RT the most common malignant tumors were tumors of the skin, breast, colon, lungs, prostate and stomach [1]. In 2015, male developed mostly tumors of the trachea, bronchi, lung $(17.8 \%)$, prostate gland $(14.4 \%)$, skin $(12.1 \%)$, stomach $(7.9 \%)$, colon $(6.1 \%)$ and rectum $(5.3 \%)$, hematopoietic and lymphatic tissue (4.8\%) [1].

The first place in terms of prevalence in the female population in 2015 belongs to breast cancer (20.9\%), followed by skin tumors (17.1\%), tumors of cervical and uterine body, placenta $(12.9 \%)$, colon $(7,1 \%)$, stomach $(5.1 \%)$, rectum, rectosigmoid junction, anus $(4.6 \%)$, ovary $(4.4 \%)[1$, p. 46 , 130]. Analysis of age and sex indicators for 2011 - 2015 testifies to the most active growth of the general oncological morbidity of the male and female population in the older age group (60 years old and older) (Fig. III, IV).

In 2015 , the ratio of morbidity rates in the same age groups of male and female population in the 0-14 age group was 1.1 (13.3 and 12.2 cases per 100,000 people of the male and female population), and in the group of 15-19 year- olds 1.4 (19.0 and 12.9 cases per 100,000 people of the male and female population). The studied rate is reduced to a minimum in the 20-39 age group and makes 0.4 (33.5 and 79.9 cases per 100,000 people of the male and female population). Due to the high incidence of tumors in the reproductive system, an increase in this indicator is observed in women in the 40-59 age group, making 0.9 (364.6, 397.6 cases per 100,000 male and female population) and in the age group of 60 and older, which is $1.8(1911.5,1053.7$ cases per 100,000 of males and females) [1].

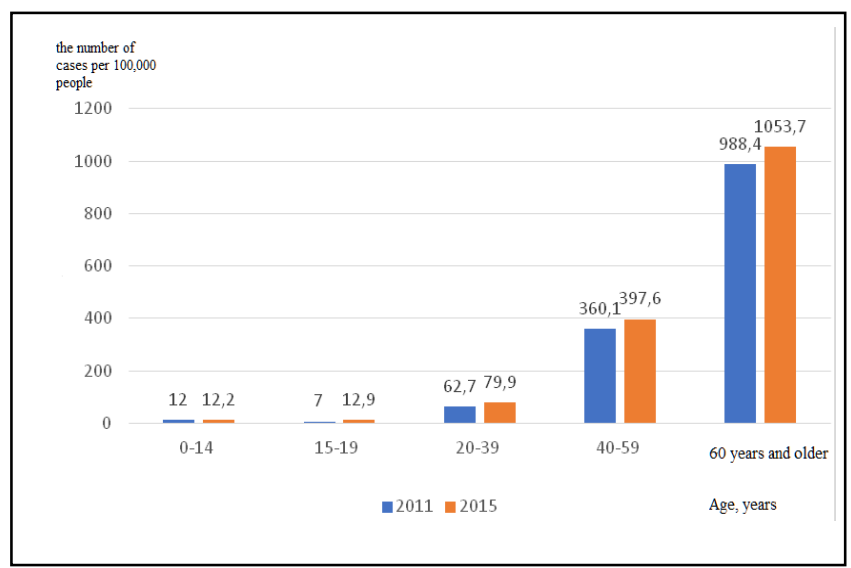

Fig. III. Age dynamics of the MNP morbidity for women in the Republic of Tatarstan for 2011-2015

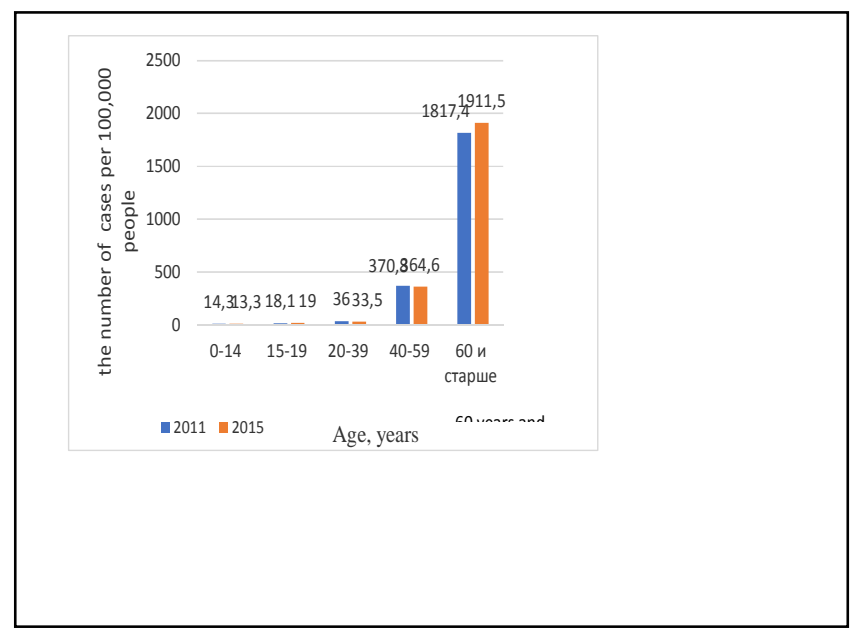

Fig. IV. Age dynamics of the MNP morbidity for men in the Republic of Tatarstan for 2011-2015

In 2015 , men in the age group of 60 years and older had an approximately 2-fold higher risk of MNP than women (1911.5 and 1053.7, respectively) [1]. This ratio of age-specific incidence rates of men and women is determined by the general trend of a higher incidence among males, it increasing proportionally to their age. One of the important indicators of oncological morbidity is the mortality rate due to oncopathology. In the Republic of Tatarstan, this indicator has been steadily growing. In 2011 and 2015, it amounted to 178.64 and 195.47 cases per 100,000 people, respectively [1]. 
In 2015, compared to 2014, there is an increase in the mortality rate by $8.4 \%$ [1]. In 2015 , compared to 2013 , the mortality rate was also higher with a growth rate of $11.9 \%$ [1]. A gradual decrease in one-year mortality is noted. In 2011, this indicator in the Republic of Tatarstan was $29.2 \%$, and in $2015-25.8 \%$ [1]. A decrease in a one-year mortality rate indicates an improvement in the quality of medical care for oncological patients. Over 2013 - 2015 this indicator decreased by $8.2 \%$ [1]. In the Republic of Tatarstan, there is also an increase in the five-year survival rate. In 2011, it was $53.3 \%$, and in $2015-55.9 \%$ [1]. 2013 - 2015 saw an increase in this indicator by $3.3 \%$ [1]. An increase in the proportion of primary MNP detected during preventive examinations indicates an improvement in the diagnosis of MNP and testifies to an increase in the rates of primary and general morbidity.

The analysis of the main statistical indicators of morbidity and mortality due to MNP in RT enables to conclude that there is an unfavorable trend in their dynamics. The state of medical care for cancer patients in the RT can be assessed as satisfactory. This requires the development of measures to improve oncological care for the population.

When studying the processes taking place in real systems, an important direction in determining the quantitative parameters of oncological diseases is the construction of models based on the data of sample surveys [4]. The solution of this problem is especially significant in the construction of mathematical models to study immune responses of the body.

The modern development level of immunology makes it possible to treat various diseases universally as an interaction of a foreign invader with a body's system of protective functions - the immunity system. This fact plays a primary role in studying pathologic processes using mathematical methods, since it enables to construct a general mathematical description of various diseases. Consideration of various diseases as processes of interaction of the immune system with pathogens allows constructing a mathematical model of some hypothetical disease, which takes into account the development patterns of a certain class of diseases [4].

Such unification explains a wide application of mathematical models and methods in this field of research. Mathematical models help to systematize the facts obtained in different studies and deal with individual aspects of the disease, to explore various immunological hypotheses, as well as to study external influences on the dynamics of the pathologic process, which is the basis for developing treatment strategy and tactics.

Depending on the purposes of modeling, ordinary differential equations, partial differential equations, stochastic differential equations can be used as models [5]. A general mathematical description of various diseases enables one to approach to the tasks of processing and interpreting clinical and laboratory data from the general positions, since their analysis can be carried out from the standpoint of a mathematical model based on the results of its theoretical studies.
Most of the practical problems associated with this are reduced to the task of determining the parameters of the constructed mathematical model by observational evidence. This is because the model parameters computed from real data are estimates of the parameters of the real body which can be targeted with drugs to provide the desired dynamics of the disease course. Within a mathematical model, by choosing parameters one can always obtain solutions interpreted as a transition from a pathologic state to a healthy state of the body. To be able to receive such transitions in the simulated system, it is necessary to know how a particular drug affects the real parameters. This can, for example, be identified if the model parameters are determined from the observation results of groups of patients receiving different doses of the drug. The study of the quantitative characteristics of the exposure to the drug on the body parameters, in particular, can serve the basis for comparing the effectiveness of various treatment methods. These characteristics enable to formulate the task of optimally managing the treatment process. [6].

Thus, when analyzing experimental data on the basis of a mathematical model of the process, the main task is to identify the parameters of the model from the observation results. This task is not new as it naturally arises in various applications [7].

If the model is a system of ordinary differential equations, then we are talking about solving the inverse problem. In the case of a probabilistic model, the solution of the problem is based on the results of the filter theory [8]. Both approaches assume that the real trajectories of the model's phase variables belong to the set of its solutions and can be obtained with some unknown set of parameters to be determined. However, it is of no less interest to consider the case when the model is deterministic, and the observational evidence is of a random nature and therefore cannot be considered as a result of modeling for a certain value of the parameter vectors. It is with this situation that the researcher is most often confronted in determining the parameters of mathematical models of diseases [9]. In this case, the random characteristics of the real values of the model variables can be due not only to the measurement error, but also to the influence of various factors that are not taken into account in the model. Therefore, in describing the real trajectories of variables, along with the measurement error, it is necessary to consider the random oscillations that take place in the system itself.

The mathematical model takes into account only those factors that determine the dynamics of the process under study and enables to explain the mechanism of the studied phenomenon. Therefore, in its construction, many inessential connections are discarded and the process under consideration is isolated, both from the system in which it flows and from the external environment. If these ideas about the mechanism of the phenomenon under study correspond to reality, then those factors that do not exert a dominant influence on the process under investigation will not be included in the model, and the model will qualitatively describe its basic laws. In the framework of the model, these factors are uncontrollable, so when describing real trajectories, their influence should be considered as random that causes trajectories deviation from the general pattern that is determined by the constructed model under some unknown set of values of its parameters [10]. 
The task of determining the parameters of mathematical models of diseases should be considered to solve applied problems related to processing the data from immunological experiments and clinical observations, for example, such as comparing the effectiveness of treatment methods or studying the effect of drugs on body parameters. From this point of view, this task is a part of a more general problem of creating a mathematical support to process clinical and laboratory data considering their features. The solution of this problem is of great importance, both theoretically and in terms of solving specific medical and biological problems [11].

In modern immunology and medicine, with intensive improvement of methods for obtaining data on the processes under study, treatment of the latter is limited to using only those methods of mathematical statistics that allow the most elementary analysis of the results of experiments and clinical observations. This seems quite natural, since a deeper analysis requires special mathematical training from the researcher. At the same time, interest on the part of mathematicians in results application is limited only to the solution of certain special problems. This is due to the fact that the application of the mathematical apparatus requires more or less formalized notions about the mechanisms of the phenomenon being studied. Such representations were absent, while the results of immunological studies did not enable to construct mathematical models to describe the processes occurring in the body during the disease. Such models are the basis on which methods of processing observational evidence can be created [12].

In clinical practice, the status of the patient is judged by the values of the indicators that form the state vector $X=\left(X^{1}\right.$, $\left.X^{2}, X^{n}\right)$ ). Its dimension $(n)$ is of the order of several tens, hundreds $(\mathrm{n} \sim 100)$. Suppose that the practical task is to study the dependence of the disease course on a certain factor (drug, age). To solve it, we need data on the dynamics of the state vector $X_{t}, t € \theta=\left(t 1, t_{2}, t_{N}\right)$, where $N \sim 10$. In order to make statistically reliable conclusions as a result of the study, it is necessary to have observations of groups of patients with a minimum $\mathrm{m} \sim 10$.

Thus, the clinician needs to rework the array of numbers with a long $\mathrm{n} \cdot \mathrm{N} \cdot \mathrm{m} \sim 104$. The introduction of the generalized index $\varphi_{t}\left(X_{t}\right)$ makes it possible to characterize the course of the disease in each patient by the state change curve $\varphi_{\mathrm{t}}\left(\mathrm{X}_{\mathrm{t}}\right)=\varphi_{\mathrm{t}}, \mathrm{t} € \theta$. The system of such curves describes the course of the disease in the selected group. The initial task is reduced to a comparison of this system, obtained by groups that were under the influence of the factor and without it. Thus, using the generalized index, it is possible to substantially simplify the problem. However, this raises two questions. First, it is a way of constructing a generalized indicator. The minimum error in the prediction of the variable of the $\mathrm{Y}$ criterion belongs to the function $\varphi_{\mathrm{t}}^{*}(\mathrm{X})=\mathrm{E}(\mathrm{Y} \mid \mathrm{X})$. In the case considered, the clinical error of the severity of the patient S condition is chosen as Y. Although this choice is justified by the long-term application of generalized indicators in clinical practice, it certainly is not the only one. On the other hand, the generalized index $\varphi(\mathrm{X})$ must be the best approximation of $\varphi^{2}(X)$.
Secondly, the construction of a generalized indicator is carried out from observational evidence, corresponding to a fixed time - the moment of the height of the disease, and in clinical practice it is successfully used to monitor the dynamics of the pathologic process [13].

Now let's assume that the components of the state vector are phase variables of the model: $(\mathrm{d} / \mathrm{dt}) \mathrm{X}_{\mathrm{t}}=\mathrm{f}\left(\mathrm{X}_{\mathrm{t}}, \alpha\right), \mathrm{X}_{0}=\mathrm{q}, \mathrm{t} €$ $(0, T), \alpha € R$. The task about the influence of the factor on the dynamics of the disease process can be solved using estimates of a parameters obtained from the trajectory system. Estimation of the model parameters leads to the construction of a linearized stochastic model describing deviations of the real values of the phase variables from the solution of the differential problem $X_{t}(\alpha)$. The possibility of such a description of deviations in each particular case can be carried out using the $\lambda^{2}$ criterion. At the same time, the question is which shifts in the estimation of the parameters are due to linearization and the replacement of a fast random variable by white noise. In addition, from a practical point of view, the criteria for choosing the observed variables and constructing the set of measurement moments $\theta$ are difficult to verify, although in specific problems they allow such an analysis [14].

The use of the most elementary mathematical methods for experimental data leads to the fact that in the course of observations, as a rule, recorded are those indicators that are only indirectly connected with the process under investigation or have nothing to do with it at all. The experiment does not measure the variables that are needed to determine the model parameters. Naturally, in such a situation it is difficult to make any reliable conclusions on the merits of the problem being solved. Such difficulties can be avoided if to carry out research jointly by experimenters and mathematicians according to a well-known scheme: setting the problem building a model - planning an experiment - analyzing the data obtained. Thus, the problem of developing mathematical methods to analyze the data of immunological experiments and clinical observations requires further research [15].

\section{References}

[1] Organization of the oncological service of the Russian Federation. URL: http://www.oncology.ru/service/organization/ (date of circulation 9.06.2017).

[2] Social sphere, Official statistics. - URL: http://tatstat.gks.ru/wps/wcm/connect/rosstat_ts/tatstat/ru/statistics/spher e/ (access date: June 9, 2017).

[3] Regions of Russia. Socio-economic indicators, 2016, URL: http://www.gks.ru/free_doc/doc_2016/region/reg-pok16.pdf (date of access : September 7, 2017).).

[4] L.N. Belykh, Analysis of mathematical models in immunology, Moscow: Nauka, 2001.

[5] I.I. Gikhman, A.V. Skorokhod, Introduction to the theory of random processes, Moscow: Nauka, 2007.

[6] F.P. Vasilyev, Lectures on methods for solving extremum problems, Moscow State University, 2004.

[7] A.K. Mitropolsky, The technique of statistical computations, M: Nauka, 2009.

[8] G. Kramer, "Mathematical methods of statistics, Moscow: Mir, 2012

[9] I.B. Pogozhev, "Application of mathematical models of diseases in clinical practice", Moscow: Nayka, 2010. 
[10] D.V. Chebikin, A.S. Funtikov, N.E. Skudin, O.M. Pavlova, A.S. Pavlov, "Comparative analysis of the dynamics of epidemiological indicators of oncological pathology in the Novosibirsk Region", Medicine and Education in Siberia: URL: http://ngmu.ru/cozo/mos/article/text_full.php?id=1074

[11] L. Welscher, Cancer: The threat persists,Medical Newspaper, № 86, pp. 37, 2012.

[12] T.M. Maksimova, V.B. Belov, Problems of social hygiene, health and history of medicine, № 1, pp. 9 -12, 2013.
[13] V.M. Merabishvili, E.I. Lalianci, O.F. Chepik, O.Yu. Subbotina, Dynamics of observed and relative survival of patients with cervical cancer (population study), Oncology issues, Vol. 58, No. 3, pp. 333-338, 2012

[14] A.D. Kaprin, V.V. Starinsky, G.V. Petrova, Malignant neoplasms in Russia in 2013 (morbidity and mortality), Moscow, 2015.

[15] A.D. Kaprin, V.V. Starinsky, G.V. Petrova, The state of oncological care for the population of Russia in 2013, M.: FGBU "MNIOI named after P.A. Herzen" of the Ministry of Health of Russia, 2014. 